\title{
Assistência Nutricional a Pacientes Hospitalizadas com Câncer de Mama e Covid-19
}

doi: https://doi.org/10.32635/2176-9745.RBC.2021v67n2.1351

\author{
Nutritional Care in Hospitalized Patients with Breast Cancer and COVID-19 \\ Asistencia Nutricional a Pacientes Hospitalizadas con Cáncer de Mama y Covid-19
}

Kissila Ferreira de Souza'; Rachel Souza Thompson Motta²

RESUMO

Introdução: Pacientes com câncer são mais suscetíveis à infecção e à maior gravidade da doença causada pelo novo coronavírus (Covid-19). Objetivo: Apresentar o cenário da assistência nutricional e o perfil clínico-nutricional de pacientes hospitalizadas com Covid-19 em uma instituição de tratamento de câncer de mama. Método: Foram apresentadas as práticas da assistência nutricional realizadas no Hospital do Câncer III do Instituto Nacional de Câncer José Alencar Gomes da Silva (HC III/INCA) durante a pandemia da Covid-19. Os dados clínicos das pacientes com câncer de mama e Covid-19 foram coletados em prontuários. Resultados: Algumas mudanças na rotina foram a suspensão das visitas dos nutricionistas em casos confirmados; a utilização de equipamentos de proteção individual; e as alteraçôes na avaliação nutricional. Um total de 23 pacientes foi incluído, sendo hipertensão a comorbidade mais comum (56,5\%) e o estadiamento clínico IV o mais frequente (43,5\%). Dispneia (60,9\%), febre (30,4\%), tosse (13\%), anemia, neutrofilia, proteína C reativa elevada, hipoalbuminemia e necessidade de oxigenioterapia durante a internação $(73,9 \%)$ foram as principais características encontradas. A maioria recebeu dieta via oral líquida $(52,2 \%)$ e, para $43,5 \%$, foi prescrito suplemento nutricional. O excesso de peso foi o estado nutricional mais prevalente. Conclusáo: Além do câncer de mama, podem se associar ao aumento do risco de complicaçóes por Covid-19 nessas pacientes a alta prevalência de comorbidades, o excesso de peso e a metástase pulmonar. A presença de sintomas que influenciam na ingestão alimentar levou à necessidade de modificaçôes na dieta para melhor aceitação alimentar.

Palavras-chave: Neoplasias da Mama; Infecções por Coronavírus; Serviço Hospitalar de Nutrição; Apoio Nutricional.

\section{ABSTRACT}

Introduction: Cancer patients are more susceptible to infection and to the greatest severity of the disease caused by the new coronavirus (COVID-19). Objective: To present the scenario of nutritional care, clinical and nutritional profile of patients hospitalized with COVID-19 in a breast cancer treatment institution. Method: The nutritional care practices performed at the Hospital of Cancer III of the National Cancer Institute José Alencar Gomes da Silva (HC III/INCA) during the COVID-19 pandemic were presented. Clinical data from patients with breast cancer and COVID-19 were collected from medical records. Results: Some changes in the routine were the suspension of consultations with the nutritionists in confirmed cases, the use of personal protective equipment and changes in nutritional assessment. A total of 23 patients were included, hypertension was the most frequent comorbidity $(56.5 \%)$, and the most frequent clinical staging was IV (43.5\%). Dyspnea (60.9\%), fever (30.4\%), cough (13\%), anemia, neutrophilia, high C-reactive protein, hypoalbuminemia and need for oxygen therapy during hospitalization $(73,9 \%)$ were the main characteristics found. The majority received a liquid oral diet $(52.2 \%)$ and $43.5 \%$ were prescribed a nutritional supplement. Overweight was the most prevalent nutritional status. Conclusion: In addition to breast cancer, an increased risk of complications from COVID-19 in these patients was associated with high prevalence of comorbidities, overweight and lung metastasis. The presence of symptoms influencing food intake led to the necessity of changes in the diet for better food acceptance.

Key words: Breast Neoplasms; Coronavirus Infections; Food Service, Hospital; Nutritional Support.

\section{RESUMEN}

Introducción: Los pacientes con cáncer son más susceptibles a la infección y a la mayor gravedad de la enfermedad provocada por el nuevo coronavirus (Covid-19). Objetivo: Presentar el escenario de asistencia nutricional y el perfil clínico y nutricional de pacientes hospitalizadas con Covid-19 en una institución de tratamiento de cáncer de mama. Método: Se presentaron las prácticas de asistencia nutricional realizadas en el Hospital do Cáncer III del Instituto Nacional del Cáncer José Alencar Gomes da Silva (HC III/INCA) durante la pandemia de Covid-19. Los datos clínicos de pacientes con cáncer de mama y Covid-19 se obtuvieron de los registros médicos. Resultados: Algunos cambios en la rutina fueron la suspensión de visitas de nutricionistas en casos confirmados, el uso de equipo de protección personal y cambios en la valoración nutricional. Se incluyeron un total de 23 pacientes, siendo la hipertensión la comorbilidad más común $(56,5 \%)$ y la estadificación clínica IV más frecuente la (43,5\%). Disnea $(60,9 \%)$, fiebre $(30,4 \%)$, tos $(13 \%)$, anemia, neutrofilia, proteína $\mathrm{C}$ reactiva alta, hipoalbuminemia y necesidad de oxigenoterapia durante la hospitalización $(73,9 \%)$ fueron las principales características encontradas. La mayoría recibió dieta líquida por vía oral $(52,2 \%)$ y al $43,5 \%$ se le prescribió un suplemento nutricional. El sobrepeso fue el estado nutricional más prevalente. Conclusión: Además del cáncer de mama, un mayor riesgo de complicaciones por Covid-19 en estas pacientes se asoció con una alta prevalencia de comorbilidades, sobrepeso y metástasis pulmonares. La presencia de síntomas que influyen en la ingesta de alimentos llevó a la necesidad de cambios en la dieta para una mejor aceptación de los alimentos.

Palabras clave: Neoplasias de la Mama; Infecciones por Coronavirus; Servicio de Alimentación en Hospital; Apoyo Nutricional.

\footnotetext{
1,2Instituto Nacional de Câncer José Alencar Gomes da Silva. Hospital do Câncer III (HC III/INCA). Rio de Janeiro (RJ), Brasil.

'E-mail: kissila-souza@live.com. Orcid iD: https://orcid.org/0000-0002-3249-8232

${ }^{2}$ E-mail rmotta@inca.gov.br. Orcid iD: https://orcid.org/0000-0002-7861-8519

Endereço para correspondência: Rachel Souza Thompson Motta. Rua Visconde de Santa Isabel, 274, $2^{\circ}$ andar - Vila Isabel. Rio de Janeiro (RJ), Brasil. CEP 20560120. E-mail:rmotta@inca.gov.br
} 


\section{INTRODUÇÃO}

Em dezembro de 2019, começou na China uma epidemia em virtude do surgimento do novo coronavírus (2019-nCoV), da síndrome respiratória aguda grave do coronavírus 2 (do inglês, severe acute respiratory syndrome coronavirus 2 - Sars-CoV-2), que causa a doença pelo coronavírus 2019 (do inglês, coronavirus disease 2019 Covid-19) ${ }^{1}$. O vírus se espalhou rapidamente pela China e por muitos outros países e, em 30 de janeiro de 2020, a Organização Mundial da Saúde (OMS) declarou que o surto do 2019-nCoV constitui uma Emergência de Saúde Pública de Importância Internacional - o mais alto nível de alerta da OMS, conforme previsto no Regulamento Sanitário Internacional ${ }^{2}$.

A transmissão da doença ocorre principalmente por gotículas respiratórias e os pacientes infectados geralmente apresentam febre e tosse seca, podendo apresentar também dificuldade em respirar, dores musculares/articulares, dor de cabeça, tontura, diarreia e náusea. Os casos graves progridem para síndrome do desconforto respiratório agudo (SDRA) ${ }^{3}$.

Todas as pessoas são passíveis ao contágio pela Covid-19, no entanto, pacientes com câncer são mais suscetíveis à infecção e à maior gravidade da doença do que indivíduos sem câncer, em razão do seu estado imunossupressor sistêmico causado pelos tratamentos anticâncer, como quimioterapia ou cirurgia, além da idade avançada ${ }^{4,5}$. Além disso, essa população apresenta um grande risco de desnutriçáo, e essa condiçáo, caracterizada principalmente pela perda de massa muscular, parece levar a piores desfechos e à maior mortalidade diante da infecção por Covid-196.

O câncer de mama é a neoplasia maligna com a maior incidência e mortalidade na população feminina mundial, representando cerca de $24,2 \%$ de todos os tipos de câncer ${ }^{7}$. O tratamento desses pacientes depende de intervençóes multidisciplinares e de alta qualidade ${ }^{8}$.

Diante da pandemia da Covid-19, são recomendadas medidas de contenção para prevenir infecçóes, tanto de pacientes quanto de profissionais da saúde. Essas açóes têm um forte impacto nos processos de rotina da equipe na assistência desses pacientes ${ }^{8}$. A falta de procedimentos nutricionais poderia, por sua vez, prolongar a recuperação dos pacientes e aumentar as complicaçôes infecciosas?

Pouco se sabe sobre o perfil e a assistência nutricional de pacientes com Covid-19, assim como a atuação profissional frente a pacientes com alto risco da infecção, como os oncológicos. É importante que seja garantida a segurança de pacientes e profissionais de saúde e assegurado o suporte necessário para uma recuperação adequada dos pacientes. Abordar as experiências nas instituiçóes torna-se necessário diante desse cenário. Sendo assim, o objetivo deste estudo é apresentar o cenário da assistência nutricional e o perfil clínico-nutricional de pacientes hospitalizadas com Covid-19 em uma instituição de tratamento de câncer de mama.

\section{MÉTODO}

Trata-se de um estudo observacional, transversal, descritivo e retrospectivo, apresentando as revisóes das práticas e protocolos assistenciais, relacionados à assistência nutricional, realizados no Hospital do Câncer III do Instituto Nacional de Câncer José Alencar Gomes da Silva (HC III/INCA) durante a pandemia de Covid-19 para as pacientes hospitalizadas com câncer de mama.

Para análise do perfil clínico-nutricional de pacientes com diagnóstico de câncer de mama e Covid-19, foram incluídas pacientes do sexo feminino, acima de 18 anos, admitidas nas enfermarias destinadas à internação de casos suspeitos e/ou confirmados da Covid-19, no período de $4 / 5 / 2020$ a 4/7/2020. Foram excluídas as pacientes com resultado negativo de swab de nasofaringe e/ou orofaringe para detecção do antígeno viral (PCR) para confirmação do diagnóstico de Covid-19, e pacientes que reiteraram no período.

Os dados sociodemográficos e da história clínica foram coletados por intermédio de consulta aos prontuários clínicos institucionais e inseridos em planilha Excel.

Analisaram-se as seguintes variáveis: idade, tempo de internação, desfecho da internação (alta, transferência para outra unidade hospitalar ou óbito), comorbidades, estadiamento clínico atual, local de progressão da doença, tipo histológico, grau histológico, receptor hormonal, receptor tipo 2 do fator de crescimento epidérmico humano (HER2), tratamento atual, exames laboratoriais (hemograma, leucograma, proteína $C$ reativa e albumina), sintomas de impacto nutricional e/ou relacionados à infecção por Covid-19, necessidade de oxigenoterapia, tipo de dieta prescrita, uso de terapia nutricional via oral e índice de massa corporal.

Para as análises dos exames laboratoriais, foram adotadas as seguintes metodologias: equipamento automatizado Horiba Pentra 60 C+ para o hemograma; método colorimétrico verde de bromocresol para a albumina sérica; nefelometria ultrassensível (monoclonal antibody against human - CRP) para PCR.

Foram considerados como pontos de corte os valores estabelecidos pelos métodos, a saber: hemácias 3,9-5,6 milhôes/dL; hemoglobina 11,5-16,4g/dL; hematócrito 36-47\%; leucócitos 4.000-10.000/ $\mathrm{mm}^{3}$; neutrófilos $1.600-7.500 / \mathrm{mm}^{3}$; PCR $<0,5 \mathrm{mg} / \mathrm{dL}$; albumina $3,5-$ $-5,2 \mathrm{~g} / \mathrm{dL}$. 
Para o índice de massa corporal, utilizou-se a classificação da $\mathrm{OMS}^{10}$ para adultos e da Organização Pan-americana da Saúde para idosos ${ }^{11}$.

A descrição da amostra foi realizada utilizando medidas de tendência central e de dispersão para as variáveis contínuas, e medida de frequência e porcentagem para as variáveis categóricas.

O estudo foi aprovado pelo Comitê de Ética em Pesquisa (CEP) do INCA para seu desenvolvimento, sob o número CAAE 35602720.5.0000.5274.

\section{RESULTADOS}

O HC III, unidade de tratamento de pacientes com câncer de mama do INCA, durante a pandemia de Covid-19, apresentou mudanças no seu funcionamento, adotando medidas de prevenção e controle na assistência aos casos suspeitos ou confirmados de infecção pelo 2019$-\mathrm{nCoV}$, orientadas por protocolo institucional.

Uma das medidas tomadas foi a implementação de uma sala de triagem de Covid-19, para onde eram encaminhados os pacientes com sintomas respiratórios, identificados na portaria por profissionais de saúde. Nessa sala, os pacientes eram avaliados por um enfermeiro e por um médico e, em caso de identificação da suspeita de Covid-19 e necessidade de internação, este era direcionado ao Serviço de Pronto Atendimento (SPA). Esses pacientes permaneceram internados no SPA até o encaminhamento a um hospital destinado ao atendimento de pacientes com Covid-19 pelo Núcleo Interno de Regulação (NIR), setor responsável pela inserção de paciente no sistema estadual de referenciamento para hospitais.

Em virtude da alta demanda desses pacientes na unidade e da dificuldade e demora da transferência para uma unidade de referência, um andar de Internação Hospitalar com dez leitos foi destinado à internação de casos suspeitos e/ou confirmados da Covid-19, a partir do dia 4/5/2020.

A equipe de assistência direta ao paciente desse andar foi reduzida aos seguintes profissionais: médico, enfermeiro, técnico de enfermagem e fisioterapeuta, visando a reduzir o fluxo de pessoal.

Outras medidas foram tomadas visando à diminuição de fluxo de pessoas e do risco de infecção intra-hospitalar. Pacientes internados nesse período não receberam visita. Recomendou-se, para pacientes internados que possuam direito previsto em lei a um acompanhante, que este não fosse pessoa caracterizada como grupo de risco para Covid-19. Profissionais que apresentassem sintomas gripais ou sintomas suspeitos de Covid-19 não deveriam comparecer ao hospital, sendo afastados administrativamente por 14 dias.

\section{ASSISTÊNCIA NUTRICIONAL}

Durante a pandemia, as visitas dos nutricionistas na beira do leito aos pacientes com suspeita ou confirmação de Covid-19 foram suspensas, de acordo com as orientaçóes da Comissão de Controle de Infecção Hospitalar (CCIH) do INCA III. A conduta nutricional foi estabelecida a partir de informaçóes coletadas com equipe médica e de enfermagem e em prontuários físicos e eletrônicos.

Para evitar o contato físico, as rotinas de triagem nutricional e avaliação antropométrica de todos os pacientes hospitalizados foram modificadas. Em pacientes com suspeita ou confirmação de Covid-19, não foram utilizadas ferramentas de triagem e de avaliação nutricional, sendo considerados todos os pacientes com Covid-19 como em risco nutricional. $\mathrm{Na}$ reavaliação diária, foram utilizados outros parâmetros, como avaliação da ingestão alimentar, sintomas de impacto nutricional, exames laboratoriais e dados clínicos dos pacientes coletados em prontuários.

As orientações nutricionais de alta hospitalar para todos os pacientes passaram a ser somente qualitativas, em razão da ausência da avaliação antropométrica, sendo baseados na anamnese nutricional exames laboratoriais, comorbidades e sintomas.

Quanto às refeiçôes dos pacientes, estas eram servidas em material descartável para evitar o compartilhamento de utensílios. As copeiras não entravam nas enfermarias com pacientes com suspeita ou confirmação de Covid-19, sendo as refeiçóes deixadas no posto de enfermagem para oferta ao paciente pela equipe de assistência direta.

\section{Perfil clínico-nUtricional de PACIentes COM diagnóstico DE CÂNCER DE MAMA E COVID-19}

No período estudado, foram admitidas 30 pacientes nas enfermarias destinadas à internação de casos suspeitos e/ou confirmados de Covid-19, sendo que sete delas apresentaram resultado negativo de swab de nasofaringe e/ou orofaringe para detecção do antígeno viral (PCR), totalizando 23 pacientes com Covid-19, confirmada na amostra.

$\mathrm{Na}$ Tabela 1, encontram-se as características gerais das pacientes com câncer de mama e Covid-19 e do período de internação. A alta hospitalar foi o desfecho mais encontrado na população, seguido de transferência hospitalar e óbito.

A hipertensão foi a comorbidade mais frequente na amostra estudada, seguida por diabetes melittus e dislipidemia. Não foram encontradas pacientes com doenças crônicas pulmonares como asma e doença pulmonar obstrutiva crônica (DPOC).

De acordo com o histórico clínico da doença, a maioria das pacientes apresentava carcinoma ductal invasivo (CDI), com receptor hormonal positivo e HER 2 negativo. 
Tabela 1. Caraterísticas gerais das pacientes com câncer de mama e Covid-19 e do período de internação em uma unidade de tratamento de câncer de mama

\begin{tabular}{|c|c|c|c|}
\hline Variáveis & $\mathbf{N}$ & Média & $\begin{array}{l}\text { Desvio- } \\
\text {-padrão }\end{array}$ \\
\hline Idade (anos) & 23 & 55,6 & 14,6 \\
\hline $\begin{array}{l}\text { Tempo de internação } \\
\text { (dias) }\end{array}$ & 23 & 6,9 & 4,2 \\
\hline Variáveis & $\mathbf{N}$ & & $\%$ \\
\hline Desfecho & 23 & & \\
\hline Óbito & 6 & & 26,1 \\
\hline Alta & 10 & & 43,5 \\
\hline Transferência & 7 & & 30,4 \\
\hline Comorbidades & 23 & & \\
\hline Hipertensão & 13 & & 56,5 \\
\hline Diabetes mellitus & 5 & & 21,7 \\
\hline Dislipidemia & 1 & & 4,3 \\
\hline $\begin{array}{l}\text { Estadiamento clínico } \\
\text { na internação }\end{array}$ & 23 & & \\
\hline EI & 1 & & 4,3 \\
\hline Ella & 2 & & 8,7 \\
\hline Ellb & 2 & & 8,7 \\
\hline Ellla & 2 & & 8,7 \\
\hline ElIIb & 6 & & 26,1 \\
\hline IV & 10 & & 43,5 \\
\hline $\begin{array}{l}\text { Local da progressão } \\
\text { da doença }\end{array}$ & 23 & & \\
\hline Pulmão/Pleura & 8 & & 34,8 \\
\hline $\begin{array}{l}\text { Sistema nervoso } \\
\text { central }\end{array}$ & 2 & & 8,7 \\
\hline Osso & 8 & & 34,8 \\
\hline Fígado & 5 & & 21,7 \\
\hline Peritônio & 1 & & 4,3 \\
\hline Tipo histológico & 23 & & \\
\hline CDI & 17 & & 73,9 \\
\hline CDI + CDIS & 4 & & 17,4 \\
\hline CLI & 1 & & 4,3 \\
\hline Carcinoma papilífero & 1 & & 4,3 \\
\hline Grau histológico & 22 & & \\
\hline 1 & 3 & & 13,6 \\
\hline 2 & 10 & & 45,5 \\
\hline 3 & 9 & & 40,9 \\
\hline RH & 22 & & \\
\hline Positivo & 15 & & 68,2 \\
\hline Negativo & 7 & & 31,8 \\
\hline HER2 & 21 & & \\
\hline Positivo & 2 & & 9,5 \\
\hline
\end{tabular}

\begin{tabular}{l|c|c}
\hline \multicolumn{1}{c|}{ Variáveis } & N & \% \\
\hline Negativo & 19 & 90,5 \\
Tratamento em curso & $\mathbf{2 3}$ & \\
na internação & & \\
Quimioterapia & 9 & 39,1 \\
Neoadjuvante & 7 & 77,8 \\
Paliativa & 2 & 22,2 \\
Hormonioterapia & 8 & 34,8 \\
Adjuvante & 5 & 62,5 \\
Paliativa & 3 & 37,5 \\
Virgem de tratamento & 2 & 8,7 \\
Controle & 2 & 8,7 \\
Cuidado paliativo & 2 & 8,7 \\
\hline
\end{tabular}

Legendas: CDI: Carcinoma ductal invasivo; CDIS: Carcinoma ductal invasivo in situ; CLI: Carcinoma lobular invasivo; RH: Receptor hormonal; HER2: Receptor tipo 2 do fator de crescimento epidérmico humano.

O estadiamento clínico IV no momento da internação foi o mais frequente; ou seja, presença de metástase para um ou mais órgãos. Os sítios de metástases mais comuns foram pulmão e/ou pleura e osso.

No momento da internação, mais de um terço do total de pacientes da amostra estavam em tratamento quimioterápico (sendo a maioria destas com finalidade neoadjuvante) e em hormonioterapia (sendo a maioria com finalidade adjuvante).

O perfil clínico-nutricional das pacientes são apresentados na Tabela 2.

Tabela 2. Perfil clínico-nutricional das pacientes com câncer de mama e Covid-19 internadas em uma unidade de tratamento de câncer de mama

\begin{tabular}{lcc|c|c}
\hline \multicolumn{1}{c|}{ Variáveis } & N & Média & $\begin{array}{c}\text { Desvio- } \\
\text {-padrão }\end{array}$ \\
\hline Hemácias & 23 & 4,0 & 0,8 \\
Hemoglobina & 23 & 11,0 & 2,0 \\
Hematócrito & 23 & 33,6 & 6,2 \\
Leucócitos & 23 & $9.234,8$ & $8.412,8$ \\
Neutrófilos & 23 & $7.700,3$ & $7.990,4$ \\
PCR & 17 & 15,1 & 10,7 \\
Albumina & 12 & 3,1 & 0,3 \\
\hline \multicolumn{1}{c}{ Variáveis } & N & \multicolumn{3}{c}{$\%$} \\
\hline Sintomas & \multicolumn{3}{|c}{30,4} \\
Constipação & 7 & \multicolumn{2}{c}{30} \\
Diarreia & 8 & \multicolumn{2}{c}{34,8} \\
Dispneia & 14 & \multicolumn{2}{c}{60,9} \\
Hiporexia & 8 & \multicolumn{2}{c}{34,8} \\
Náuseas & 10 & \multicolumn{2}{c}{43,5} \\
Vômitos & 7 & \multicolumn{2}{c}{30,4} \\
\hline
\end{tabular}




\begin{tabular}{|c|c|c|}
\hline Variáveis & $\mathbf{N}$ & $\%$ \\
\hline Disgeusia & 1 & 4,3 \\
\hline Mucosite & 2 & 8,7 \\
\hline Febre & 7 & 30,4 \\
\hline Tosse & 3 & 13,0 \\
\hline Cefaleia & 3 & 13,0 \\
\hline $\begin{array}{l}\text { Oxigenioterapia na } \\
\text { admissão }\end{array}$ & 11 & 47,8 \\
\hline Cateter tipo óculos & 10 & 43,5 \\
\hline $\begin{array}{l}\text { Máscara com } \\
\text { reservatório }\end{array}$ & 1 & 4,3 \\
\hline $\begin{array}{l}\text { Necessidade de } \\
\text { oxigenioterapia } \\
\text { durante a internação }\end{array}$ & 17 & 73,9 \\
\hline Ventilação mecânica & 5 & 29,4 \\
\hline \multicolumn{3}{|l|}{$\begin{array}{l}\text { Características da } \\
\text { dieta na internação }\end{array}$} \\
\hline \multicolumn{3}{|l|}{$\begin{array}{l}\text { Via da dieta na } \\
\text { admissão }\end{array}$} \\
\hline Oral & 23 & 100,0 \\
\hline \multicolumn{3}{|l|}{$\begin{array}{l}\text { Mudança na via } \\
\text { da dieta durante } \\
\text { internação }\end{array}$} \\
\hline Zero & 7 & 30,4 \\
\hline CNE & 3 & 13,0 \\
\hline $\begin{array}{l}\text { Consistência da dieta } \\
\text { VO na admissão }\end{array}$ & 23 & 100 \\
\hline Líquida & 12 & 52,2 \\
\hline Pastosa & 2 & 8,7 \\
\hline Branda & 8 & 34,8 \\
\hline Normal & 1 & 4,3 \\
\hline $\begin{array}{l}\text { Mudança na } \\
\text { consistência da } \\
\text { dieta VO durante } \\
\text { internação }\end{array}$ & 14 & 60,9 \\
\hline Líquida para pastosa & 1 & 7,1 \\
\hline Líquida para branda & 3 & 21,4 \\
\hline Pastosa para líquida & 3 & 21,4 \\
\hline $\begin{array}{l}\text { Uso de terapia } \\
\text { nutricional VO }\end{array}$ & 10 & 43,5 \\
\hline IMC & 10 & 43,5 \\
\hline Baixo peso & 1 & 10,0 \\
\hline Eutrofia & 2 & 20,0 \\
\hline Sobrepeso & 2 & 20,0 \\
\hline Obesidade & 5 & 50,0 \\
\hline
\end{tabular}

Legendas: PCR: Proteína C reativa; CNE: Cateter nasoentérico; VO: Via oral; IMC: Índice de massa corporal.

$\mathrm{Na}$ avaliação dos exames laboratoriais, nota-se que, em média, os níveis de hemoglobina e hematócrito estavam abaixo do valor de referência, enquanto a média dos níveis de neutrófilos estava acima. Somente 17 pacientes da amostra tinham resultado de PCR disponível e 12 pacientes de albumina. A média de PCR foi elevada nessas pacientes, e a média de albumina foi abaixo do valor de referência utilizado na instituição.

A maioria das pacientes do presente estudo apresentou na admissão queixa de dispneia, sendo este o sintoma mais frequente. Outros sintomas comumente relacionados à Covid-19 e que podem causar impacto nutricional, como febre, tosse, náuseas, vômitos, diarreia e cefaleia, também estavam presentes.

$\mathrm{Na}$ admissão, a oxigenoterapia via cateter tipo óculos foi necessária para $43,5 \%$ das pacientes, enquanto uma paciente necessitou máscara com reservatório. Durante a internação, grande parte das pacientes necessitou de oxigenoterapia, entre as quais, quase $30,0 \%$ necessitaram de ventilação mecânica.

No que concerne às características da dieta, todas as pacientes estavam com dieta via oral no momento da admissão, sendo que a maioria delas recebeu dieta líquida, e parcela importante necessitou de prescrição de suplementos via oral.

No decorrer da internação, foi necessária a mudança na consistência da dieta para mais da metade das pacientes, de acordo com os sintomas apresentados ao longo do período. Ademais, algumas pacientes evoluíram com piora clínica importante, sendo necessária a suspensáo da dieta via oral, porém somente para três delas foi possível iniciar terapia nutricional via cateter nasoentérico.

Dados de antropometria (peso e altura) para cálculo do IMC estavam disponíveis para menos da metade da amostra, com destaque para o excesso de peso.

\section{DISCUSSÃO}

Os nutricionistas não passaram visitas na beira do leito aos pacientes com suspeita ou confirmação de Covid-19. O Conselho Federal de Nutricionistas recomenda que seja evitado o contato físico do nutricionista com pacientes suspeitos ou confirmados com Covid-19 no ambiente hospitalar. Essa mudança tem o objetivo de proteger a saúde dos profissionais e da populaçáo em geral ${ }^{12}$.

Não foram utilizadas ferramentas de triagem nutricional e avaliação antropométrica, sendo todos os pacientes considerados como em risco nutricional. A necessidade de manutenção da realização de métodos de avaliação antropométrica deve ser avaliada criteriosamente por se tratar de uma população de risco por conta da imunossupressão apresentada $^{13}$. A Sociedade Brasileira de Nutrição Oncológica ${ }^{14}$ recomenda que, caso náo seja possível realizar a triagem nutricional, considere todos os pacientes oncológicos com Covid-19 confirmados como em risco nutricional. 
A média de idade das pacientes no presente estudo foi de 55,6 \pm 14,6 anos. Vuagnat et al. ${ }^{15}$, em estudo com 59 pacientes com câncer de mama e Covid-19 acompanhadas em um hospital francês, encontraram uma média de idade de 58 anos, valor próximo ao encontrado no presente estudo, e ocorrência de óbito em apenas $6,7 \%$ das pacientes, valor inferior ao do presente estudo, que foi de $26,1 \%$.

A maioria das pacientes apresentava hipertensão. Evidências mostram que existe um risco aumentado de agravamento da Covid-19 em pacientes com hipertensão, diabetes, doença cardiovascular, doença cerebrovascular e $\mathrm{DPOC}^{16}$.

A maioria das pacientes apresentava CDI. Os carcinomas invasivos ductais e lobulares são as formas mais comuns de câncer de mama. Dados de prevalência apontam que o CDI varia de $50 \%$ a $75 \%$ de todas as neoplasias invasivas da mama $^{17}$.

O estadiamento clínico mais frequente foi o IV, sendo os sítios metastáticos mais comuns o pulmão/pleura e osso. Pacientes com câncer de pulmão são mais propensos a desenvolver anoxia mais grave e a progredir mais rapidamente com Covid-19, indicando uma necessidade urgente e aumentada de tratar pacientes com câncer infectados por Covid-19, com ênfase especial em pacientes com câncer de pulmão ${ }^{18}$.

Mais de um terço do total de pacientes da amostra estava em tratamento quimioterápico e em hormonioterapia. É amplamente aceito que os pacientes com câncer podem ter uma imunidade enfraquecida secundária à sua neoplasia subjacente ou aos tratamentos anticâncer. Em particular, o recebimento de quimioterapia (nos últimos três meses) ou radioterapia extensa em curso predispõe pacientes com câncer à infecçáo por Sars-CoV-2 e complicaçóes graves de Covid-19, tornando as medidas de prevenção de infecção para esses subgrupos vulneráveis fundamentais. A exigência clínica, a intenção do tratamento, a extensão prevista do benefício terapêutico, a biologia da doença e os fatores do paciente influenciam a priorização dos tratamentos do câncer durante a era Covid-19 ${ }^{19-21}$.

Estudos mostram que as alteraçôes laboratoriais mais frequentes em pacientes com Covid-19 são o aumento da PCR, diminuição da albumina sérica e contagem total de leucócitos com considerável variação, por vezes, aparecendo alta ou diminuída, mas com evidente presença de linfopenia. Há também diminuição da hemoglobina. Além disso, a anemia e a hipoproteinemia são consideradas consequências da deterioração nutricional em pacientes com câncer, o que pode afetar adversamente a imunocompetência e aumentar a suscetibilidade a patógenos respiratórios ${ }^{18,22}$.

A maioria das pacientes apresentou na admissáo queixa de dispneia. Destaca-se que o tratamento sintomático mais importante para pacientes com Covid-19 é a oxigenoterapia. A alta proporção de pacientes com Covid-19 com câncer, que requerem oxigenoterapia e ventilaçáo mecânica, pode estar relacionada à doença mais grave e a um estado imunossupressor, sendo mais suscetíveis à infecção pulmonar secundária por outros patógenos ${ }^{23}$.

Todas as pacientes estavam com dieta via oral no momento da admissão, sendo a maioria dieta líquida, e parcela importante necessitou de prescrição de suplementos via oral. A mudança na consistência da dieta ocorreu para mais da metade das pacientes. Os pacientes oncológicos e com Covid-19 cursam com diversos sintomas que implicam na ingestáo alimentar. É recomendado considerar a sintomatologia apresentada pelo paciente na avaliação e no monitoramento nutricional para instituir adaptaçóes dietéticas, visando à promoção da adequada aceitação alimentar ${ }^{24}$.

Suplementos nutricionais orais devem ser usados sempre que possível para atender às necessidades do paciente, quando o aconselhamento dietético e a fortificação de alimentos não são suficientes para aumentar a ingestáo alimentar e atingir as metas nutricionais ${ }^{6}$.

$\mathrm{O}$ excesso de peso foi mais frequente nas pacientes em que foi possível calcular o IMC. Em mulheres com câncer de mama é comum o ganho de peso após o diagnóstico, ocorrendo em $50 \%$ a $95 \%$ das pacientes. Tanto as pacientes que estão acima do peso no diagnóstico quanto as pacientes que ganham peso durante o tratamento têm pior prognóstico, com o aumento do risco de recorrência da doença e da mortalidade ${ }^{25}$.

Hussain et al. ${ }^{26}$ conduziram um estudo de metanálise com objetivo de investigar se pacientes com obesidade têm maior probabilidade de morrer de Covid-19, em comparação com indivíduos não obesos, e concluíram que a obesidade é um fator de risco para mortalidade em pacientes com o vírus ${ }^{26}$.

Para melhor assistência e conduta nutricional durante a pandemia de Covid-19, o trabalho em equipe multidisciplinar é fundamental. As informaçôes coletadas pela equipe de assistência direta ao paciente são essenciais para determinar as características da dieta, a via de alimentação, a implementação de terapia nutricional, e assim possibilitar uma intervenção nutricional precoce, evitando o risco de desnutriçáo e consequentemente melhor prognóstico dos pacientes oncológicos que contraem a Covid-19.

O estudo possui algumas limitaçôes, como o tamanho pequeno da amostra e o desenho retrospectivo e descritivo, porém se mostra relevante por causa da escassez de estudos que abordem o perfil e a assistência nutricional a pacientes com Covid-19 e câncer de mama. Salienta-se ainda a 
necessidade de se compartilhar experiências referentes ao atendimento nutricional desses pacientes, a fim de aperfeiçoar cada vez mais a prática clínica diante de uma doença nova.

\section{CONCLUSÃO}

No atual cenário da pandemia de Covid-19, foram necessárias mudanças importantes nas rotinas institucionais, para prevenção e controle da infecçáo dentro do ambiente hospitalar, visando à diminuição do risco de contágio entre profissionais e pacientes.

As pacientes com câncer de mama podem ter um risco aumentado de complicaçôes por Covid-19 pela doença de base. Podem se associar ao aumento desse risco uma alta prevalência de comorbidades, excesso de peso e a progressão de doença para sítios que comprometem ainda mais a função respiratória, como o pulmão e a pleura.

A presença de sintomas que influenciam na ingestão alimentar, como dispneia, tosse e náuseas, se mostrou muito frequente nas pacientes com Covid-19 e câncer de mama, levando à necessidade de modificaçóes na consistência da dieta para melhor aceitação alimentar, sendo necessária a terapia nutricional via oral para aquelas pacientes com ingestão alimentar insuficiente.

A ausência do nutricionista na equipe de assistência direta ao paciente é superada pelo trabalho em equipe multidisciplinar, o que possibilita que as informaçôes referentes à condiçáo clínica do paciente sejam repassadas e que a melhor conduta seja tomada para manutenção ou recuperação do estado nutricional do paciente.

\section{CONTRIBUIÇÕES}

Ambas as autoras contribuíram na concepção e/ ou no planejamento do estudo; na obtençâo, análise e interpretação dos dados; assim como na redação e revisão crítica; e aprovaram a versão final a ser publicada.

\section{DECLARAÇÃO DE CONFLITO DE INTERESSES}

Nada a declarar.

\section{FONTES DE FINANCIAMENTO}

Não há.

\section{REFERÊNCIAS}

1. Guo YR, Cao QD, Hong ZS, et al. The origin, transmission and clinical therapies on coronavirus disease 2019 (COVID-19) outbreak - an update on the status. Mil Med Res. 2020;7(1):11. doi: https://doi. org/10.1186/s40779-020-00240-0
2. Organização Pan-Americana da Saúde [Internet]. Brasília, DF: OPAS; [2000]. Folha informativa sobre COVID-19; [acesso 2020 nov 23]. Disponível em: https://www.paho.org/pt/covid19

3. Tay MZ, Poh CM, Rénia L, et al. The trinity of COVID-19: immunity, inflammation and intervention. Nat Rev Immunol. 2020;20(6):363-74. doi: https://doi. org/10.1038/s41577-020-0311-8

4. Liang W, Guan W, Chen R, et al. Cancer patients in SARS-CoV-2 infection: a nationwide analysis in China. Lancet Oncol. 2020;21(3):335-37. doi: https://doi. org/10.1016/S1470-2045(20)30096-6

5. Wang H, Zhang L. Risk of COVID-19 for patients with cancer. Lancet Oncol. 2020;21(4):E181. doi: https://doi. org/10.1016/S1470-2045(20)30149-2

6. Barazzoni R, Bischoff SC, Breda J, et al. ESPEN expert statements and practical guidance for nutritional management of individuals with SARS-CoV-2 infection. Clin Nutr. 2020;39(6):1631-38. doi: https://doi. org/10.1016/j.clnu.2020.03.022

7. Bray F, Ferlay J, Soerjomataram I, et al. Global cancer statistics 2018: GLOBOCAN estimates of incidence and mortality worldwide for 36 cancers in 185 countries. CA Cancer J Clin. 2018;68(6):394-424. doi: https://doi. org/10.3322/caac. 21492

8. Curigliano G, Cardoso MJ, Poortmans P, et al. Recommendations for triage, prioritization and treatment of breast cancer patients during the COVID-19 pandemic. Breast. 2020;52:8-16. doi: https://doi. org/10.1016/j.breast.2020.04.006

9. Cintoni M, Rinninella E, Annetta MG, et al. Nutritional management in hospital setting during SARS-CoV-2 pandemic: a real-life experience. Eur J Clin Nutr. 2020;74(5):846-7. doi: https://doi.org/10.1038/s41430020-0625-4

10. World Health Organization. Obesity: preventing and managing the global epidemic: report of a WHO consultation [Internet]. Geneva, Switzerland: WHO; 2000 [cited 2021 Jan 14]. (WHO technical report series; 894). Available from: https://apps.who.int/iris/ handle/10665/42330

11. Organización Panamericana de la Salud, División de Promoción y Protección de la Salud (HPP). Encuesta Multicéntrica salud bienestar y envejecimiento (SABE) en América Latina y el Caribe: informe preliminar [Internet]. In: 36 Reunión del Comité asesor de investigaciones em Salud; 2001 jun 9-11; Kingston, Jamaica: OPAS; 2001. Washington, D.C.: Organización Panamericana de la Salud; 2001 [acesso 2021 jan 15]. Disponível em: https://www1.paho.org/Spanish/HDP/ HDR/CAIS-01-05.PDF

12. Conselho Federal de Nutricionistas (BR). Recomendaçôes do CFN: boas práticas para a atuação do nutricionista e do técnico em nutrição e dietética durante a pandemia 
do novo coronavírus (COVID-19) [Internet]. 3 ed. rev. ampl. Brasília, DF: CFN; 2020 [acesso 2020 nov 27]. Disponível em: https://www.cfn.org.br/wp-content/ uploads/2020/03/nota_coronavirus_3-1.pdf

13. Nabarrete JM, D'Almeida CA, Castro MG, et al. Recomendaçôes nutricionais para o paciente com oncológico durante a pandemia do Coronavírus (COVID-19). BRASPEN J. 2020;35(1):9-12. doi: https://doi.org/10.37111/braspenj.AE2020351002

14. Martucci RB, Cardoso AMC, Gallon CW, et al. Nota Técnica da Sociedade Brasileira de Nutrição Oncológica sobre os cuidados nutricionais em oncologia frente à pandemia de Covid-19. Rev Bras Cancerol. 2020;66(Tema Atual):e-1011. doi: https://doi.org/10.32635/21769745.RBC.2020v66nTemaAtual.1011

15. Vuagnat P, Frelaut M, Ramtohul T, et al. COVID-19 in breast cancer patients: a cohort at the Institut Curie hospitals in the Paris area. Breast Cancer Res. 2020;22:55. doi: https://doi.org/10.1186/s13058-020-01293-8

16. Wang B, Li R, Lu Z, et al. Does comorbidity increase the risk of patients with COVID-19: evidence from metaanalysis. Aging (Albany NY). 2020;12(7):6049-57. doi: https://doi.org/10.18632/aging.103000

17. Gonçalves LLC, Santos SB, Marinho EC, et al. Câncer de mama feminino: aspectos clínicos e patológicos dos casos cadastrados de 2005 a 2008 num serviço público de oncologia de Sergipe. Rev Bras Saude Mater Infant. 2012;12(1):47-54. doi: https://doi.org/10.1590/S151938292012000100005

18. Zhang L, Zhu F, Xie L, et al. Clinical characteristics of COVID-19-infected cancer patients: a retrospective case study in three hospitals within Wuhan, China. Ann Oncol. 2020;31(7):894-901. doi: https://doi. org/10.1016/j.annonc.2020.03.296

19. Chan JJ, Sim Y, Ow SGW, et al. The impact of COVID-19 on and recommendations for breast cancer care: the Singapore experience. Endocr Relat Cancer. 2020;27(9):R307-R327. doi: https://doi.org/10.1530/ ERC-20-0157

20. European Society for Medical Oncology [Internet]. Lugano, CH: ESMO; c2020. What should medical oncologists know about COVID-19?; [cited $2020 \mathrm{Nov}$ 27]. Available from: https://www.esmo.org/covid-19and-cancer/q-a-on-covid-19

21. Yu J, Ouyang W, Chua MLK, et al. SARS-CoV-2 transmission in patients with cancer at a tertiary care hospital in Wuhan, China. JAMA Oncol. 2020;6(7):110810. doi: https://doi.org/10.1001/jamaoncol.2020.0980

22. Xavier AR, Silva JS, Almeida JPCL, et al. COVID-19: manifestaçóes clínicas e laboratoriais na infecção pelo novo coronavírus. J Bras Patol Med Lab. 2020;56:1-9. doi: http://doi.org/10.5935/1676-2444.20200049

23. Liu C, Zhao Y, Okwan-Duodu D, et al. COVID-19 in cancer patients: risk, clinical features, and management.
Cancer Biol Med. 2020;17(3):519-27. doi: http://doi. org/10.20892/j.issn.2095-3941.2020.0289

24. Piovacari SMF, Santos GFCG, Santana GA, et al. Fluxo de assistência nutricional para pacientes admitidos com COVID-19 e SCOVID-19 em unidade hospitalar. BRASPEN J. 2020;35(1):6-8. doi: http://doi. org/10.37111/braspenj.AE2020351001

25. Champ CE, Volek JS, Siglin J, et al. Weight gain, metabolic syndrome, and breast cancer recurrence: are dietary recommendations supported by the data? Int J Breast Cancer. 2012;2012:506868. doi: http://doi. org/10.1155/2012/506868

26. Hussain A, Mahawar K, Xia Z, et al. Obesity and mortality of COVID-19. Meta-analysis. Obes Res Clin Pract. 2020;14(4):295-300. doi: http://doi. org/10.1016/j.orcp.2020.07.002 